\title{
Digitalization for Sustainable Development of Small Towns in Russia
}

\author{
Tatiana A. Guzhavina*
}

\begin{abstract}
Digitalization has become a significant trend in the development of modern humanity. The pandemic has accelerated the digitalization of most countries. They contribute to the development of new practices, open up new opportunities for communication. They also require certain skills and competencies, education. But digital environment affects people in different ways. It creates new problems and restrictions, increases risks, including increasing social inequalities. It can expand access to information, include a person in the global space, but it can also limit the world to the diagonal of a digital device. It is important to understand how the population is ready for these changes, what real opportunities it has. The digital environment is emerging in modern cities, where inclusion in it is faster. Ahead are megacities, industrial and administrative centers. But almost two thirds of the cities are small towns, where one fourth of the population of Russia lives. What are the opportunities for digitalization for the population of small towns, what are the restrictions for residents to be included in the digital space. The purpose of our study is to assess the state of digital competence of the population of small towns in the Russian Federation on the basis of their self-assessment of their readiness to function in a digital environment. The empirical basis of the study was the results of a survey conducted among the urban population of the Vologda region on a representative sample with quotas by gender and age. The study showed that there are problems in the development of the necessary competencies by residents of small towns to use the digital space.
\end{abstract}

Keywords: sustainable development, digitalization, region, small towns.

\section{Introduction.}

Digitalization creates a new social environment that requires an individual to improve their education and master new interaction practices. Digitalization has covered the entire planet. Every second inhabitant of the earth is connected to the Internet. According to experts, the effects of digitalization are quite comparable to the effects of the industrial revolution, which managed to form the leadership of countries in the world economy, which is preserved to this day.

Digital economy is seen as a powerful resource for the further technological development of Russia. Today, in terms of number of users, Russia ranks first in Europe and eighth in the world ${ }^{1}$. Thus, Russia acquired a chance to become a leader in the digital world and to realize its economic potential. The following facts testify to Russia's readiness for life in a digital environment. According to the UN International Telecommunication Union, among 176 countries in the ICT development index, Russia ranks 45th (index 70.7)2

\footnotetext{
${ }^{1}$ Internet World Statistic / URL: https://www.internetworldstats.com/top20.htm
}

${ }^{2}$ Russia in it ratings / URL: https://www.tadviser.ru/index.php 
Russia is in the 32nd place according to the UN composite e-government index (index 0.7998 with a maximum value of 1 ). Russia is among the 11 countries with the highest EGDL score. Russia ranks 23rd in terms of citizen engagement (the so-called electronic participation, E-Participation). In the ranking of telecommunications infrastructure, the country scored 0.6219 points in 2018 against 0.6091 two years earlier. ${ }^{3}$

Thus, according to international ratings, Russia occupies a fairly high position, shows the presence of potential for its development in this direction. These characteristics were taken into account when changing the paradigm of the country's economic development. The Russian Federation has developed and adopted for implementation the "Strategy for the Development of the Information Society in the Russian Federation for 2017 - 2030"4

Like many countries, Russia was affected by the problem of decreasing growth reserves, which made itself felt back in the 70 s of the last century, when the rates of productivity growth in developed countries began to decline significantly. At the beginning of the XXI century, growth began to be no more than $1 \%$ per year ${ }^{5}$. According to economists, the reason for this state of affairs is associated with the operation of the law of falling returns on investment and with the excess of fixed assets. The decline in labor productivity was especially great in the manufacturing industry, which is a systemic customer and consumer of products of innovative technological industries [Uskov, 2019]. In this regard, the digital economy has come to be seen as a powerful resource for further technological development.

\section{Theoretical Underpinnings}

The information society paradigm became popular in the 70s of the twentieth century in Europe and USA. It was formed thanks to the efforts of a number of scientists. Among them are D. Bell, Z. Brzezinski, E. Giddens, M. Kasetls, E. Masuda, E. Toffler, A. Touraine, J. Habermas and others. The term "information society" was coined by E. Masuda. He carried out one of the most interesting and profound developments in the framework of the concept of the information society, showing the continuity between the post-industrial and information society. He argued that knowledge and information become key factors of development, which will lead to a change in the very essence of production and to the creation of an information-intensive product [Masuda, 1998]. In describing the new society, E. Masuda focused on economic aspects. But he did not rule out possible changes in its value bases. He saw the future society as «a society of Concord, with a small government and a state apparatus» [Masuda, 1981]. D. Bell called the distinctive feature of post-industrial society the decline in the role of material production, the development of the service and information sectors. This will create a different nature of human activity, change the types of resources involved in production, and lead to a transformation of the social structure. He divided social relations and technologies,

\footnotetext{
${ }^{3}$ United Nations E-Government Survey. 2018 / https://www.un.org/development/desa/publications/2018un-e-government-survey.html

4 Strategy for the development of the information society in the Russian Federation for 2017-2030 https://www.garant.ru/products/ipo/prime/doc/71570570

${ }^{5}$ New technological revolution: challenges and opportunities for Russia: expert analysis. docl. / / URL: https://strategy.csr.ru/user/pages/researches/novaya-tehnologicheskaya-revolutsiya-2017-10-13.pdf
} 
considering them to be independent variables [Bell, 1999]. M. Castels is a leading theorist of the information (digital) society. To denote its distinctive features, he used various concepts/ and wrote that this is necessary " ... because the very fact of increasing the volume of information and its movement between actors and different points is what defines a new era» [Castells, 2009]. M. Castells notes an orientation towards technological development, knowledge accumulation and a higher level of information processing [Castells, 2009]. There is actually a merging of capitalism and the information revolution. And as a result, according to Castells, a network society emerges, in which networks connect individuals, institutions and organizations and states [Castells, 2010]. Despite the fact that the information society is studied by many branches of knowledge, a single concept has not been formed. E. Toffler linked the emergence of the information society with the change of stages of development, when industry is replaced by the information sector of the economy. E. Toffler argued that information connections will prevail in society over industrial ones and the knowledge factor will become the leading one [Toffler, 1980].

Russian scientists began to study information, its role in the life of society. Research on the information society was the next step. Currently, Russian science has developed several theoretical models of the information society. Most of them were created in the $90 \mathrm{~s}$ of the twentieth century.

A systematic approach has become widespread among Russian scientists. They consider the information society as a system with qualitatively new principles of organization, which is at a higher level [Abdeev, 1994]. In the state, the power of information and the power of intelligence will be present in all branches of government.

Russian scientists drew attention to a number of important characteristics of a new type of society, including new technologies, robotics, the need for innovative infrastructure designed for the dissemination, accumulation and processing of information. Rakitov also identified such a feature as the availability of information regardless of the spatial location of its consumer. According to scientists, at least 50\% of the population should be employed in the production and redistribution of information [Rakitov, 1991]. Russian scientists consider the information society as a post-economic one. Its features are the weakening of the role of the market, the destruction of value relations, the gradual displacement and replacement of private property by personal property, the growth of the share of creative professions. [nozemtsev, 2001].

Another Russian scientist L. Lutsenko, identified as the most important features of the information society the specifics of managing public processes, changes in the quality of life, recreation, education, and health care. Many researchers note that the necessary infrastructure is essential for the development of the information society. It includes a system of information resources, services and communications necessary for the dissemination, accumulation and processing of information [Lutsenko, 2010]. The theory of the information society has significantly enriched the understanding of the basic characteristics and manifestations in various spheres of life. But multiple interpretations do not form a single picture. This is due to the fact that there are new aspects that need to be studied.

Russian scientists have drawn attention to an important aspect related to the need to form the subjects of a new society [Popova, 2018; Sadovaya, 2018; Yablokova, 2018]. A person 
is considered as an object. some scientists refer to the subject as an artificial intellect. The reason is that he can make his own decisions. A person enters the so-called digital or virtual space, which requires him to master new forms of communication, master new practices and ways to protect his personal digital sovereignty and personal data. Communication processes in this case are implemented using the terminology of M. Castells, through communication protocols and according to certain standards that determine the production, processing, transmission and storage of information. Communication began to be carried out by using programs of network processes installed in technical devices.

The digital environment requires digital literacy from a person, which includes digital competencies, digital consumption and digital security [Berman, 2017]. Digital literacy is based on digital competencies, which allow solving various problems in the use of information and communication technologies (ICT), as well as using and creating content using digital technologies, including searching and sharing information, answering questions, interacting with other people, and a number of other characteristics. Thanks to them, the individual has the opportunity to use the digital environment for various purposes.

An individual as a subject of a digital society enters the so-called digital space. In the digital space, the individual must ensure the protection of his personal digital sovereignty over personal data, learn new practices. In the digital space, a person acquires different characteristics and a different legal status. He needs new knowledge, new truths. As a digital subject, an individual learns a new culture of interaction, new values, new status positions. The subject has new functions in network communication systems [Nazarchuk, 2008].

\section{Environment for the formation and application of digital competencies}

The Ministry of digital development, communications and mass communications of the Russian Federation claims that the level of digital literacy of the country's population in 2018 was $58 \%$, and by 2024 this figure will reach $75 \% \%^{6}$. To solve this problem, it is necessary to ensure public access to digital technologies and create a digital infrastructure. The Russian Federation occupies a significant area, so the distances between cities are large. there are many cities in Russia. But 2/3 of them are small towns.

Living in large cities creates more favorable conditions for access to the digital environment and actively stimulates the development of digital competencies. For small cities there are a number of constraints that are technical and social in nature. There is not enough high quality of communication, which creates restrictions in access to the Internet. There are some limitations in the needs for using online services. Other specific factors may also have an impact.

Vologda region is considered one of the most developed regions of the North-Western Federal district. Its economy can be characterized as various. The region has developed transport and tourist infrastructure. There are industrial enterprises and shopping centers, agriculture and food industry. But the region lags behind in terms of digitalization.

6 Ministry of digital development, communications and mass communications of the Russian Federation: ofic. website. URL: https://digital.gov.ru/activity/directions/540 
Especially small towns. The region consists of 15 cities and 8 urban-type settlements. They are the centers of municipalities. A small town is a city with a population of up to 50 thousand people. This number of inhabitants forms a very significant social group of society, which determines the importance and necessity of its research.

\section{Research Methodology}

In our study, we proceed from the following theses. Firstly, the concept of sustainable development and the cluster approach makes it possible to study the situation at the regional level. Secondly, non-material factors are of the same importance as material ones. Thirdly, the population of large countries, such as the Russian Federation, is largely concentrated in small towns, whose residents are interested in the development of their settlements. Fourthly, among the population of small towns, there are trends of inclusion in the digital space, the acquisition of digital skills and competencies is taking place. With appropriate support from the state, these processes will be successful and will become a factor in the sustainable development of territories. The purpose of our study is to assess the state of digital competence of the population of small towns in the Russian Federation, to identify the existing limitations.

Taking into account the importance of the formation of digital competencies, government agencies, consulting companies, individual researchers are developing their models. Widespread are: "European model of digital competencies for education", "Model of digital competencies for citizens of the European Union." The "Target Competency Model 2025" by BCG was also developed based on the consensus opinion of experts and an analysis of the approaches of the Lominger Competence Library, Sberbank, RosExpert / Korn Ferry, NRU-HSE, WorldSkills Russia and Global Education Future 7 . This model, along with technical skills, includes cognitive and social behavioral components.

For a preliminary assessment of the level of digital literacy of the population of small towns in the region, we identified a group of competencies based on these models, and carried out their operationalization (Table 1). Indicators that allow obtaining the data necessary for research are highlighted.

Table 1. Digital competencies, their interpretation and operationalization

\begin{tabular}{|l|l|l|}
\hline $\begin{array}{l}\text { Areas of } \\
\text { competence }\end{array}$ & Competence & Indicator \\
\hline $\begin{array}{l}\text { Information } \\
\text { literacy }\end{array}$ & $\begin{array}{l}\text { Technical competence } \\
\text { (ability to use a gadget) }\end{array}$ & $\begin{array}{l}\text { Tell us what of the following you have done } \\
\text {-Use your smartphone }\end{array}$ \\
\cline { 2 - 3 } & $\begin{array}{l}\text { Cognitive Competence } \\
\text { Browsing and Searching } \\
\text { Information) }\end{array}$ & $\begin{array}{l}\text { Tell us what of the following have you done: } \\
\text {-Use the Internet for information, shopping, } \\
\text { ordering tickets }\end{array}$ \\
\hline
\end{tabular}

${ }^{7}$ Digital skills training: Global challenges and best practices. Analytical report for the III International conference " More than training: how to develop digital skills" / URL: https://edutechclub.sberbank-school.ru/system/files/event/pdf 


\begin{tabular}{|l|l|l|}
\hline $\begin{array}{l}\text { Behavioral competence (use } \\
\text { of personal account - PA) }\end{array}$ & $\begin{array}{l}\text { Tell us what of the following you have done: } \\
\text { - use your Personal account on public Services, } \\
\text { tax inspection, housing and utilities websites, } \\
\text { etc.) } \\
\text { What is the most effective way to solve a social } \\
\text { problem that affects the interests of many } \\
\text { citizens? } \\
- \text { post an appeal to the authorities and all } \\
\text { concerned on the Internet }\end{array}$ \\
\hline Compiled by the author
\end{tabular}

The selected indicators are used to analyze the empirical data of a sociological survey conducted in the Vologda region. The general population is the urban population of the region. The total urban population is 860,000 . The sample is representative, with quotas by gender and age. The sample size is 1,900 people over the age of 18 . The research method is a questionnaire. Respondents living in cities were interviewed. The selection of respondents was random. The study was conducted in 2019. We have studied various aspects of life in the region, including carried out a preliminary assessment of the level of digital literacy.

\section{Research data}

The first group of competencies included in information literacy is technical competencies. Today, smartphones are very popular, which are Internet devices that allow a person to be mobile and quickly receive the necessary information. This is a rather complex multifunctional device with an operating system. As a result of the analysis of empirical data, information was obtained on the digital literacy of the population of small cities. Most citizens own and use smartphones. This was reported by $80 \%$ of respondents. This indicates that they have technical competencies. In large cities, their share is higher; it is $88 \%$.

These competencies are most often mastered independently, since there are no training programs or courses. Help is often provided by experienced friends or acquaintances. However, in this case, the functions of the apparatus are used partially, which may affect the development and use of other groups of necessary competencies. This group of competencies includes not only the ability to activate a gadget, but also use the functions of the operating system, such as entering a request, saving information. transition from site to site, viewing video content, etc.

The second group of competencies belongs to the category of cognitive ones. Cognitive competencies are associated with the cognitive activity of an individual and are associated with such processes as solving problems of an everyday or professional nature, production, storage and dissemination of information. The ability to extract and accumulate information is a distinctive feature of human activity and a condition for the development of society. In many ways, these competencies are the result of self-development and selfeducation. The area of manifestation of this competence in the framework of digital 
literacy is quite extensive. This competence allows you to select information in accordance with the goals set, analyse its content, assess the adequacy, reliability and reliability of the source, interpret the information, and apply it in further actions. Its indicator in our study was the answer variant mentioning the search for information, making purchases, ordering tickets, etc. As the survey data show, more than half of the residents of large cities use the Internet for these purposes $(53 \%)$. However, only a third of residents of small towns seek information or shop online (table 2).

Table 2. Distribution of respondents' answers to the question "Tell me, which of the following have you done over the past two or three years?" (\% of the number of respondents)

\begin{tabular}{|l|l|l|}
\hline Answer choice & Big cities & Small cities \\
\hline Use your smartphone & 88 & 80 \\
\hline $\begin{array}{l}\text { Use the Internet for information, purchases, ordering } \\
\text { tickets, etc. }\end{array}$ & 53 & 35 \\
\hline Use your Personal account & 47 & 43 \\
\hline Send requests to the municipality & 2 & 3 \\
\hline None of the above & 5 & 10 \\
\hline
\end{tabular}

Less involvement of residents of small towns in the region is explained by living conditions. A small population, lower incomes, and a smaller proportion of young people among residents serve as a barrier and do little to promote the demand for such online practices as delivery, booking tickets for cultural events, and paying for goods and services by card in their locality. Residents of small towns, many prefer to do it in person.

The third group of competencies consists of behavioral practices. The indicators of these competencies were the answers to the question about the use of the personal account (PA) and the practice of sending complaints to municipalities in an online format. About half of the respondents are quite successful in using PA to get government services or interact with tax authorities. The range of public services is wide enough. The PA allows a citizen of the Russian Federation to receive certificates, register property, car, etc. (table 2). An increase in the number of users should be expected due to the increase in the volume of services provided under the digital government project.

Digital literacy is also linked to civic engagement-oriented communications. In the Russian Federation, all authorities and institutions have open online contacts for citizens to apply. Every citizen can write an appeal. But so far, few people turn to municipalities via the Internet (table 2).

But from 30 to $40 \%$ of respondents are ready to address the authorities and all those who are not indifferent to solving an important problem (table 3). 
Table 3. Distribution of respondents 'answers to the question "What is The most effective way to solve a social problem that affects the interests of many citizens? " ( $\%$ of the number of respondents)

\begin{tabular}{|l|l|l|}
\hline Answer choice & Big cities & Small cities \\
\hline $\begin{array}{l}\text { Post an appeal to the authorities and all concerned on the } \\
\text { Internet }\end{array}$ & 40 & 41 \\
\hline
\end{tabular}

It is obvious that in the future these practices will be developed more widely, which will be greatly facilitated by restrictions on direct communication of people in connection with the pandemic. The situation itself will encourage the population to develop this type of communication. But even here there is a technical limitation. It is not always convenient to use a smartphone to send various applications and requests. A desktop computer is required. Its absence also serves as a restriction on the use of e-government portals.

In this group of competencies, we can also distinguish those that are focused on communication and cooperation. This requires skills in the field of interaction using digital technologies (table 4). Citizens are not just included in social networks; they interact in a virtual space. About $10 \%$ of respondents are quite actively involved in the functioning of groups created in social networks, in network events (promotions, discussions, content creation, reposts, etc.). Residents of large cities are more involved in the network interaction, but also residents of small towns acquire this experience.

Table 4. Distribution of respondents 'answers to the question " Do You take part in public and political events? " ( $\%$ of the number of respondents)

\begin{tabular}{|c|c|c|}
\hline Answer choice & Big cities & Small cities \\
\hline \multicolumn{3}{|c|}{$\begin{array}{l}\text { Some group that communicates only via the Internet (for example, Vkontakte, Instagram, } \\
\text { Odnoklassniki, Facebook) }\end{array}$} \\
\hline Regularly & 12 & 8 \\
\hline From time to time & 21 & 9 \\
\hline Once & 4 & 6 \\
\hline Never & 63 & 76 \\
\hline \multicolumn{3}{|c|}{ Discussion of socially significant issues in the Internet environment } \\
\hline Regularly & 4 & 2 \\
\hline From time to time & 15 & 10 \\
\hline Once & 3 & 6 \\
\hline Never & 80 & 80 \\
\hline
\end{tabular}


According to the data obtained, almost two-thirds of respondents are not active in network interaction and do not realize their cognitive competencies. This is also evidenced by the answers to the question about participation in the discussion of socially significant problems.

\section{Conclusion}

The concept of sustainable development is an important area of human development. The methodological basis of the concept is a triad approach to the interpretation of sustainable development through the unity of environmental, economic and social. Digitalization fits perfectly into this triad. As a process, it requires two conditions. First, the availability of a digital device and, secondly, the skills and abilities to use. The contradiction of modernity is that the pace of computerization is faster than the pace of human acquisition of the necessary skills. The impact of digitalization extends to all spheres of public life. It changes technology, management and penetrates into everyday practice. Digitalization forms a person as a subject of a new digital reality. Therefore, you need to know what skills a modern person has, what competencies he has mastered, and what needs to be learned.

Small towns, being the basis for the socio-economic development of the regions of the Russian Federation, play an important role in the process of sustainable and stable development of the entire country. At the same time, regional and global processes of social development affect the internal problems of small towns. Therefore, small territories need to adapt to modern realities and look for opportunities to create better living conditions for the population, attract investment and qualified personnel, and develop urban infrastructure. Digitalization can contribute to this in many ways.

A large part of the region's population is already involved in the use of digital technologies. But the level of possession of the necessary skills is insufficient. As the research data show, there are a number of restrictions for residents of small towns, both objective and subjective. The lower standard of living of the population of small cities, their territorial remoteness reduces the need for certain types of online practices. There is no point in booking a ticket if there is no way to go somewhere. Close interpersonal contacts in small settlements make online communication less popular both between individual citizens and between citizens and local authorities. The socio-demographic factor is important. Old and older people do not use these practices or use them in a limited way. Especially distrust among them is caused by online banking. Accommodation in private homes and contacts with management companies are also limited. Nevertheless, the experience of using the portals of state Services and the Federal tax service will be expanded. This was especially facilitated by the situation of the coronavirus pandemic, when a significant part of people found themselves in self-isolation. The pandemic gave a strong impetus to the spread of online education, strengthened network communication. First of all, it affected students and schoolchildren. And through them, the spread of digital competencies will be extended to older age groups of the population.

Thus, the spread of digital literacy will create new opportunities for small-town residents to realize their life aspirations. Of course, the assessment of digital literacy obtained by the method of a sociological survey should be supplemented with other indicators and 
indicators of an objective nature. But despite the limitations, this approach allows you to get information about the available opportunities and limitations, which can become the basis of management decisions for the development of the human potential of small cities in the region.

\section{Acknowledgments}

Article prepared with the support of the Russian Foundation for Basic Research, grant "Collective Actions and Social Capital in Russian Society" Project No. 20-011-00326 / 20.

\section{References}

Abdeev R.F. (1994). Philosophy of information civilization. M.: VLADOS. 336 p.

Bell D. 1999. The Coming of Post-Industrial Society. New York: Basic Books.

Berman N.D. (2017). On the issue of digital literacy // Modern studies of social problems. V.8. No. 6-2. P. 35-38.

Castells, M. (1996, second edition 2009). The Rise of the Network Society, The Information Age: Economy, Society and Culture Vol. I. Malden, MA; Oxford, UK: Blackwell.

Castells, M. (1998, second edition, 2010). End of Millennium, The Information Age: Economy, Society and Culture Vol. III. Malden, MA; Oxford, UK: Blackwell.

Inozemtsev V.L. (2001). One World Divided. Existing Causes and Possible Results of the Coming PostEconomic Revolution. London, Wisdom House. 482 p.

Lutsenko L. M. 2010. Concepts of information society and social function of information // Values and meanings. No. 5 (8). Pp. 136-152.

Masuda Y. (1981). The Informational Society as Post-Industrial Society. Washington: World Future Society. $171 \mathrm{p}$.

Masuda Y. (1998). Computeropia. 358 p.

Nazarchuk A.V. (2008) Network society and its philosophical understanding / / Voprosy filosofii. Vol. 7. Pp. 61-75

Popova A.V. (2018). New subjects of information society and knowledge society: on the issue of normative legal regulation // Journal of Russian law. No. 11. Pp. 14-24.

Rakitov A.I. (1991). Philosophy of the computer revolution. M.: Politizdat, 287 p.

Sadovaya E. S. (2018). The Person in a digital society: the dynamics of socio-labour relations // South-Russian magazine of social Sciences. Vol. 19. No. 3. Pp. 6-20.

Toffler, A. (1980). The third wave/ New York: Morrow. 544 p.

Uskov V.S. Trends in the formation of the problem of the development of the digital economy in Russia / Problems of the development of territories. 2019. No. 2 (100). S.53-66.

Yablokova N. I. (2018). Subjects of network society: socio-philosophical analysis // Social and political Sciences. No. 5. P. 101-103. 